\title{
Mice Ping Ping, as a example to analyse the animation derivatives market in Wuhan
}

\author{
JunMei Zeng ${ }^{1, a^{*}, \text { NingYuan Zhang }}{ }^{2, b}$ \\ ${ }^{1}$ Xi'an Polytechnic University, Xi'an,China \\ ${ }^{2}$ Xi'an Polytechnic University, Xi'an,China \\ a445263856@qq.com, b646112351@qq.com
}

Keywords: Animation Derivatives investment revenue

\begin{abstract}
This paper mainly talks about the original animation -- mice Ping Ping which made by the media of Wuhan dolphin to analyze Wuhan animation derivatives market, and further expand into China derivatives market. Chinese animation, though started early, has not developed into a complete industrial system. Many animation masterpiece had won good reputation and awards, but did not recover costs that led to losses and collapse. Many manufacturers can not operate Animation without the state funding. It is one of the most important reasons that derivatives market did not develop well. Recently, The success of Pleasant Goat and Big Big Wolf,Monkey King : Hero is back and other films has encouraged other Chinese animation manufacturers. The paper in order to make use of Wuhan market as a example, comparing the Chinese and foreign to discusses the development of the road of derivatives markets.
\end{abstract}

\section{The Operations and the market value of derivatives animation}

Animation derivatives industry refers to using the authorization of original image in the cartoon, a series of services or products which developed and manufactured by professional designers. On the one hand,animation derivative products including novels, games, toys and so on,on the other hand,deeper meaning may go into wider range of areas by authorized way, such as 3D animation products.

The main return on animation investment comes from the issuance and sale of animation derivatives, the profits maybe several times higher than the original products or even several tens of times. For example, The Lion King of Disney animation, earned \$760 million, videotapes earned \$ 780 million, and the merchandise licensing revenue have \$ 6 billion. Merchandise licensing program including books stationery, toys, household, clothing, beverages, food, etc. In these industries, there are more than 2,000 individual products can be licensed at least. Each authorization item obtain $\$ 3$ million at least, and it will get $\$ 6$ billion license revenue from 2000 authorization items at least. So animation derivatives is the most critical aspect in animation industry chain, and the animation derivatives market is the main task of the development of animation industry. Excellent animation derivative products can not only create considerable income, but also improve the brand image of animation products.

Cartoon derivative products are divided into two types: one is for viewing, Memorial and entertainment, with some commemorative and collectible value and appreciation of space. Mainly rely on the intangible value of brand image to support. The other is household items that derived from the cartoon, such derivatives has the dual advantage of practical and emotional, not only close to people's lives, but also can shape consumers' emotion and experience. To realize the derived value from a part of the way is to produce development departments within the enterprise to achieve and from the other part of the way is through brand licensing, to derivative operations for the proxy manufacturers, processors, etc.

Statistics show that animated film derivatives revenue growing trend in 2013 Chinese, but the growth of box office income of every animated film is very uneven. The highest single-animated film 
derivatives revenues reached $50 \%$ of total revenue, the rest of the increase is less than $10 \%$ of the overall revenue.

\section{The case study of mice ping ping}

\section{Mice Ping Ping Animation Overview}

Mice Ping Ping spent more than 20 million, which lasted five years to buithe first independent innovation full-length 3D animation in Hubei's by Wuhan dolphin media. Dolphin Media belongs to Hubei Yangtze River Publishing Media Group, the largest professional children's books published in one of the publisher. The animation division founded in 2001, digital content development is one of the priorities of its development, has already become an independent commercial operation with capacity of animation team. Currently, it has authorized the signing of a number of world brands, comprehensive agent Disney, Warner, diffuse Viagra, Sesame Street and other world-famous classical books.

The film is a modern village for the story background, mice Pingping, including 12 animal characters for the protagonist, standing on the perspective of the child, show Pingping and its friends in everyday life, the story of each episode contains a phrase and real life philosophy. Up to now, it has been favored by Italy, Singapore, Spain, Canada and other countries.

\section{Brand marketing strategy}

1). Dolphin Media is targeted in children and adolescents about 0-18 years of age, the main games of which are puzzle, children literature, cartoon pictures, Infant enlightenment and other eight categories, and is divided into high, medium, low price product development for the different needs. In 2008, the company's editorial department developed into the newsroom editor planning center from a previous development, its development of five Division based on the product line, plan to launch more than 300 kinds of books in annually.

2) Value implementation is the most fundamental element that makes creative industries differentiate from creative cultural, and only generate the value through application and distribution of cultural and creative will be able to form the concept of cultural creativity conception. Dolphin Media which implemented the spirit of the origin since it was set up, insisted to the path of the original animation,throughout the development of Chinese animation industry, most of the works imitated the success of the US and Japanese animation, so the original will be more valuable in this environment.

3) Usually there are three roads for animation: film animation, quasi-film animation and television animation.The United States of Disney, DreamWorks Animation is the main representative of the film; the quasi-film animation television is broadcast tablets that starts to shoot the movie; television animation mainly living in public goods, TV animation has a strong market potential, if you want impressed the audience,many animated episodes are dominant. To analysis from the point of television programming effectiveness and social impact, the animation that have quality assurance of long-term broadcast on television will achieve better social benefit,Dolphin Media also chosen this path, acquired by CCTV for 1000 yuan / minutes of "price", and achieved high ratings.

\section{Problems and Solutions exist}

1). ROI is low. To focus too much on the quality of technical and animation, in the planning stage, there is no consideration in the later publicity and derivatives explotation which led to the animation can easily be gradually forgotten in the CCTV after the broadcast finished, missed the most profitable segment of the animation industry chain, $70 \%$ of the profits in the most of the cartoons are from derivatives, so this is what we must take into account in the part of pre-planning. Dolphins media should rely on the advantage of Wuhan which is being Shanghai and zhejiang radiation belts. The large quantity of goods delivered to Shanghai and Zhejiang region that have a stronger purchasing power. The region of Shanghai and Zhejiang has more small and medium light industry enterprises, can greatly reduce the manufacturing cost of derivatives.

2) Each animation will have its own audience, while mice Ping Ping make the script of the story by standing in the perspective of child, each episode of theme is based on a phrase, and then teach 
children with a relatively innocent straightforward way, that means derivatives consumer groups positioning to the children groups that under the age of 12 years, and when we analyze this group, we can find that they generally have a strong desire of cartoon derivative products, and acceptance is also very strong, but their consuming capacity largely influenced by parents, the ability to discern cartoon characters and quality of animation products is very low. To face this kind of consumer groups, the animation products should not be developed into a high-end product, partly because of the spending power, the other is that high-end products have a serious shortage of attractive for the group. In the planning stage,therefore, the Dolphin Media should take full advantage, create derivatives of digital book class, and contact to some manufacturers, such as stationery, clothing companies, brand authorization, so that they can participate in the investing and financing of derivatives, and it will not only get a large profit, but also to enhance the commercial value of the animation brands.

From a psychological point of view, consumers relax body and mind in the entertainment, find themselves in watching or escape from reality in the virtual image; from a cultural point of view, belongingness and rebellious, coordination and difference, individuality and commonality is always maintained a tension.

On the significance of industrial economics, media program operate the program and also audience, the core of "commercial aesthetics" of the original animation is to respect the requirements of the audience, located original animation production by the audience demand response,animation production also needs the market test. Because the sentiment of audiences consumer for original animation is a "slow accumulation, slow release" process, starting with original animation, and translate animation consumers into derivatives consumers, it is the common policy to maximize the value of industrial.

3) derivative value realization, is the magnifying of the value of original animation. The specific process and modalities to implement, part of the company through internal development departments to achieve, part of it is through the "brand licensing" ,to operate derivative activities by licensed to dealers, processors, etc. Disney, for example, after completed an original animated film, first , to won the recognition and love from audiences and consumers by worldwide publicity and networks distribution, and its value is reflected as a box office revenue; the second step, works further into the book, DVD and interactive products, to be a second round of spread by publishing and distributing. Finally, the animated image of authority related to the agent to operate - With its strong brand, relying on patent protection, and create greater value with agents, licensees and customers.

Also in China, Naughty Blue Cat 3000 Questions and radiant and the Wolf functions very well. Naughty Blue Cat 3000 Questions has been taken the Disney line of derivatives animated, such as books, clothing, backpacks, watches, lunch boxes, theme parks ,to expand interests that animation brings to their own step by step.

But Sunchime Cartoon believes Disney's line also needs improvement. Sunchime Cartoon have synthesized the operate way of Disney,Nike and War-Mart ,using the Disney brand licensing; doing some design concepts with procurement and processing like Nike;authorizing stores sell the blue cat out as the products like Wal-Mart.

In this era of the Internet, the platform network have to take seriously. Now, the fiery animation whether it is radiant and the Wolf or bear-infested attach great importance to the network platform. Domestic animation picture of bad people had already get a lot of harvest relying on network broadcast, coupled with app,such new phone platform, make its revenue more expanded.

\section{The animation derivatives market in Wuhan}

\section{The initial formation of Wuhan animation industry chain}

Two years ago, Wuhan's animation journal Circulation ranking third in all the world., Wuhan Animation Association statistics show that Wuhan's animation journal Circulation has rose to second in the world in 2013. The 2012 anime association annual meeting at the beginning of 2013, delegates from a very wide range of industries, showing the initial integration of a huge animation industry 
chain in Wuhan. Comic journals, literary journals, film and television animation, engineering animation, children's books and books peripherals, computer games, mobile games, film dubbing, professional education, universities, artists and their teams, independent producer and so on.In the annual report, Zhang Min, the president of Wuhan Institute Of Animation use a Introduction that is not familiar for everyone -- ACG (animation, comics, games, and all associated peripheral products) to summarize this increasingly shaping industry chain.

\section{Hubei animation derivatives}

\section{Policy Environment.}

Hubei provincial government attaches great importance to the animation industry, Hubei provincial government pay high attention to the animation industry, and clearly put forward the goal which is to develop the animation industry into the industry leading position and enter the first phalanx during the Eleventh Five-Year. At the same time, the government introduces preferential policies, such as tax reduction and exemption, to provide financing and technical support for the animation business. The provincial government will hold the departmental joint conferenced which led by the Department of Culture, and participated by provincial relevant departments to support the development animation industry, to establish a joint meeting system. The Consideration has approved The advice to promote the development of the animation industry in our province and Each department division of duties to support the development of animation industry in Hubei, strengthening the guidance of the animation industry. Wuhan also attaches great importance to the development of animation industry, clearly stated "to focus resources to create synergy, forming composition forces, to take the East Lake High-tech Zone as a base,and the animation industry as a breakthrough,to construct Wuhan digital creative industry base" and issued a Wuhan animation industry development plan and policy on accelerating the development of animation industry in Wuhan and other policy documents. At present, the Wuhan Donghu New Technology Development Zone Optical Valley has initially established a large-scale animation industrial park, It has changed the scattered, weak pattern of animation creative industries preliminary, and attracted a number of industry-leading animation companies settled get together, such as Jiang Toon Animation. The park has preliminarily formed the industry chain that composed by animation product development, originality, production, operations and peripheral product development, opened the prelude of large-scale development of creative industries.

\section{Social Environment.}

"Wuhan, China's International Anime Fair" is cultural animation brand, committed by Wuhan, which is a large cartoon cultural activities that based on animation works, and target groups for teenagers .It has already hold three terms of "Optical Valley International Animation Festival". Optics Valley Animation Festival has become the largest of the central region, with the highest level and most influential, and the best market-oriented Animation game theme exhibition. By the end of 2014, Wuhan has four animation enterprises successfully landed the third edition, animation and game industry total output value reached 5.4 billion yuan in 2014 .

\section{Talent Environment.}

Wuhan is the science, education and talent power, the third-largest educational center, also an important training base of animation talent in our country. With the warming of animation industry in recent years, the tertiary institutions have opened animation professionals in Wuhan, it has formed a complete education system from specialist to graduate-level. These schools trained a large number of outstanding animation talent, that has become the backbone and valuable asset of Hubei animation industry.

\section{Investment Environment.}

Wuhan mainly take the industrial town with three zones and six suburbs as the industrial agglomeration area, formed four industry sectors and nine industrial clusters. Industry is the first place in Wuhan economic work. The industry formed four growth poles relying on the region and existing industrial : Large Optical Valley region, Chinese car city, airport economic zone and port 
industrial area. These four industrial zones has laid a good foundation for the development of Wuhan animation derivatives industry.

\section{Problems and Solutions}

\section{build diversified investment and financing system.}

Currently, the big problem in animation industry is the lack of funds, and huge amounts of money often does not flow to the animation industry. Most of the size of the animation companies are relatively small, so the loan funds and pull the enterprise investment are both difficult. If Wuhan wants to reduce the risk, government, banks should actively encourage some large enterprises, the private financial capital or financial institutions, banks in Wuhan involved in equity investment, holding, merger of the way to enter the animation industry, participated in various types of animation products development and creative production, expand financing channels. For example, China Film animation industry business model, came up with storyboards and animation image at first,and then provided to helped the developers and investors, find a good suitable investment enterprises, but also paved a way out for themselves, has a certain prediction for overseas markets and grasp of the project is also very mature, so investors are relatively easy to follow up the money, and the profits is also great, so there will be more investors willing to invest in them.

The scale and efficiency of Wuhan Foreign companies has been in continuous growth, and therefore, it can attract a number of foreign international companies, but also can learn foreign advanced technology and business model.

\section{The quality consciousness of product development.}

It is necessary to take the brand line,create their own unique brand,and the development of peripheral products is also a means of maintaining its independence and development,If animation and creative want to do well. Beijing's famous animation company "Green Tree" is standing in a relatively high altitude, Dedicated to the production of high-quality animation original works, the creation of brand to brand as the engine, by setup means of domestic and international distribution channels synchronization,to build the market structure which take issue authorization and animation derivatives as sales system, to achieve the profit model of Integration of industrial chain that from originality, production, distribution to the animation derivatives industry.

All manuscripts must be in English, also the table and figure texts, otherwise we cannot publish your paper.

Please keep a second copy of your manuscript in your office. When receiving the paper, we assume that the corresponding authors grant us the copyright to use the paper for the book or journal in question. Should authors use tables or figures from other Publications, they must ask the corresponding publishers to grant them the right to publish this material in their paper.

Use italic for emphasizing a word or phrase. Do not use boldface typing or capital letters except for section headings (cf. remarks on section headings, below).

\section{Summary}

Wuhan animation industry started late, but stagnated for such a long time. Although the momentum is fierce at this stage, there are also a lot of problems. Industrialization is still immature in its infancy. Too few outstanding companies like Dolphin Media, and there are many problems of the company's commercial operation, the whole industry also doesn't have a good marketalizational management mechanism. It results in many strong companies that can not achieve the creation of original animation, can only become a behind of foreign companies.Even appeared the phenomenon that more good reputation animations get less money, but poor reputation animations get more money.

Wuhan animation industry is boomingly developing, there always have some new excellent animation appears every year, and excellent animation companies are also increasing. Outstanding animation film also shows good strength on the cinema box office. For example, Monkey King: Hero 
is back accounted for one-third of the summer box office this year, it has broken the box office of one hundred million mark for only $13 \%$ of the piece rate in three days. Eventually he won the 956 million yuan at the box office, becoming the Chinese animated film box office champion. It has showed the good prospects for animated films, and mostly ages domain development of Chinese film, and we strongly believe that Chinese film will usher in a new era of all-ages.

\section{References}

[1] JiaGuo Li,Research On Structure Optimization Of Chinese Animation Industry,Nanjing:Nanjing University Press,2012.3.

[2] Masuda Hiromichi (Japan),translated by Xiwang Li,Business Operation Mode Of Japanese Animation Industry,Beijing:Longman book,2012.

[3] Yizhong Wang,Animation Industry Management System Theory,Beijing:China University Of Communication Press,2011.10.

[4] Shuping Yu,Wuhan And Chinese Film,Beijing:China Film Press,2013.9.

[5] Yuejun Liu,Cartoon Character Brand Operation,Beijing:Beijing Normal University Press,2009.

[6] Chao Qin,Animation Marketing,Beijing:Tsinghua University Press,2013.7.

[7] Lili Luan,Cartoon Derivative Product In The Perspective Of Humanistic Concern,Wuhan:Wuhan University Press,2013.11.

[8] Sheng Shen,Nationalization:The Only Way For The Development Of Chinese Animation Industry,Beijing: People's Publishing House,2013.

[9] Shujiao Chen,Wei Wei,Construction Of Animation Industry Chain A Case Study Of Beijing Animation Industry,Beijing:China Social Science Press,2013.6. 